la revue La revue pour l'histoire du CNRS

POUR LHISTORE DU CNRS $\quad 24 \mid 2009$

Soixante-dixième anniversaire du CNRS

\title{
Le CNRS célèbre son soixante-dixième anniversaire
}

André Kaspi

\section{(2penEdition}

Journals

Édition électronique

URL : https://journals.openedition.org/histoire-cnrs/9138

DOI : 10.4000/histoire-cnrs.9138

ISSN : 1955-2408

Éditeur

CNRS Éditions

Édition imprimée

Date de publication : 5 octobre 2009

ISSN : 1298-9800

Référence électronique

André Kaspi, "Le CNRS célèbre son soixante-dixième anniversaire », La revue pour l'histoire du CNRS

[En ligne], 24 | 2009, mis en ligne le 05 octobre 2009, consulté le 20 mai 2021. URL : http://

journals.openedition.org/histoire-cnrs/9138; DOI : https://doi.org/10.4000/histoire-cnrs.9138

Ce document a été généré automatiquement le 20 mai 2021.

Comité pour l'histoire du CNRS 


\title{
Le CNRS célèbre son soixante- dixième anniversaire
}

\author{
André Kaspi
}

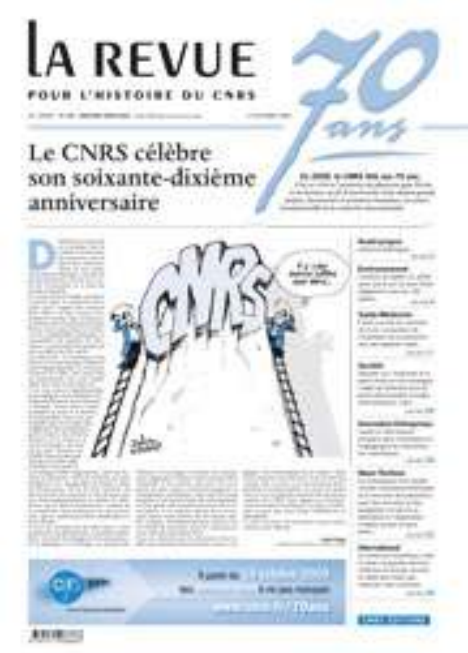

Depuis qu'il a été créé le 19 octobre 1939, le CNRS a traversé bien des épreuves, mis en place des réformes, douté de son avenir, surmonté les obstacles, recruté de jeunes chercheurs, lié son sort à celui de l'Université et à celui du monde industriel.

1 Il n'a pas cessé d'occuper une place centrale dans la recherche française, qu'il s'agisse des sciences dites dures ou des sciences humaines et sociales. Que seraient aujourd'hui nos connaissances si Jean Perrin n'avait pas réussi à convaincre les responsables politiques, à rassembler des équipes de chercheurs, à concrétiser un projet qui naît au début $\mathrm{du} \mathrm{XX}^{\mathrm{e}}$ siècle?

2 Les épreuves, les réussites et les échecs n'ont pas manqué d'illustrer cette longue période. La revue pour l'histoire du CNRS, elle aussi, fête un anniversaire. En cette année 2009 , elle vient d'avoir dix ans.

3 C'est une raison supplémentaire pour expliquer notre initiative. Exceptionnellement, notre formule a changé. Nous avons choisi d'adopter le style et le format d'un 
quotidien. Avec cette particularité que nos articles sont rédigés par des scientifiques, qu'ils traitent des diverses facettes de la science et qu'ils évoquent, de près ou de loin, l'histoire du CNRS. Nous n'avons pas décidé de tomber dans la facilité ni de céder à une insupportable vulgarisation. Que nos lecteurs se rassurent! Nous les invitons en toute simplicité à un voyage dans le temps et dans les laboratoires. Au fil de leurs lectures, ils découvriront des hommes et des femmes qui ont choisi passionnément le métier de chercheur, qui le disent franchement, comme ils le ressentent, sans forfanterie ni circonvolution, qui ne cachent pas leurs satisfactions et leurs doutes.

4 À ceux qui accepteront de nous suivre, nous proposons une promenade, à grandes enjambées, à travers les champs de la connaissance, de la physique à la biologie, en passant par l'histoire, la sociologie, la chimie, les sciences pour l'ingénieur et bien d'autres secteurs de la recherche. C'est comme cela que l'on comprend un peu mieux comment progresse la connaissance scientifique, quels sont les coups de génie et les fausses joies, les interrogations en tout genre que suscitent découvertes et innovations. À ce numéro spécial de la revue, nous avons voulu donner un ton enjoué, parfois ludique, fondamentalement sérieux. En ces temps de morosité, nous ne cédons pas à je ne sais quel optimisme béat.

5 Nous ne sommes pas les docteurs Tout-Va-Bien qui chaussent leurs lunettes roses et négligent « les tristes pépins de la réalité ». Mais nous résistons aux docteurs Tout-VaMal qui voient tout en noir et ne parviennent pas à prendre le recul nécessaire. Les uns et les autres ont eu tort au long des soixante-dix premières années du CNRS. Avec rigueur et sincérité, nous racontons une histoire, la vôtre, la nôtre, qui ne peut pas nous laisser indifférents ni désespérés.

6 À vous, lecteurs, de nous dire si nous avons atteint notre objectif.

\section{AUTEUR}

\section{ANDRÉ KASPI}

Président du Comité pour l'histoire du CNRS 